\title{
Professor Hassan Saidi; A Pillar of the Annals of African Surgery
}

Bahaty Riogi ${ }^{1}$, James Kigera ${ }^{2}$

1. Kisii Teaching and Referral Hospital\& International Fellow-St Helens and Knowsley Teaching Hospital, Liverpool, UK.

2. School of Medicine, University of Nairobi

Correspondence to: Dr. Bahaty Riogi P.O Box 13449-00100 Nairobi, Kenya. Email: drbahaty@gmail.com

Key Words: Mentorship, Workshops

Ann AfrSurg 2018; 15(2):44-45

DOI:http://dx.doi.org/10.4314/aas.v15i2.1

Conflicts of Interest: None

It is not every day that one gets a chance to eulogise their mentor on a platform their mentor founded; which is exactly what we have chosen to do with this issue. Prof Hassan Saidi can be described as the backbone of Annals of African Surgery (AAS), an open access journal published by the Surgical Society of Kenya (SSK). He proposed its formation during the 2006 Annual General Meeting (AGM) of the SSK and formally launched it in 2007 at the time, a very new concept for the society and its members. This first issue had authors who cut across all levels of surgical career; from medical officers to professors and surgical specialities from general surgery to cardiothoracic surgery(1).There was a concern about the sustainability of the idea given that surgeons were poor at converting their clinical work into research. He however, had a vision to have this misconception changed. Through his vision, the AAS is currently appreciated as "one of the premier surgical reads" in the continent (2).

His role in the journal did not end with being its founding editor in chief (EIC); he recognised the need to build a pool of researchers, authors, reviewers and editors for the journal to be successful. To achieve this, he embarked on a journey to ensure that the next generation of stakeholders were equipped with the skills to handle the tasks that lay ahead of them. To groom authors, he organised workshops on the side-lines of each SSK annual meeting. These free workshops were invaluable in imparting the skills of scientific writing to its attendees. The participation and output of these workshops has increased with members from other
Funding: None

(C) 2018 Author. This work is licensed under the Creative Commons Attribution 4.0 International License.

attendees. The participation and output of these workshops has increased with members from other medical specialties such as obstetrics and gynaecology. The effect of these events is felt when it is determined that about a third of papers published have been submitted by workshop attendees.

Prof Saidi was admired by many trainee and junior surgeons; many of whom wanted to be supervised by his genius mind through their theses, mainly because of his active involvement in the process. He was all rounded in research with the ability of guiding an author through the different stages of research writing. He was known to stimulate the students mind to think of a problem or gap within the practice and come up with a research question and a solution for it. He had a talent of opening the student's mind to the clinical and operating environment and thus demystifying the myth that research is complex. He was known to read through the whole manuscript and giving input as detailed as grammar corrections; a skill not possessed by many of his colleagues in the faculty. He was more than willing to review articles and give expert opinion be it a dissertation proposal or audit report even when he wasn't an author. All these qualities have been described by Ojuka and Kobe where his skills were not limited to teaching research but also in surgery itself and personal influence on his trainees and colleagues $(3,4)$.

He demonstrated deep passion and interest in young authors be they medical students or professors who had minimal experience in scientific publications. As the 
EIC of the AAS he was empathetic towards these young publishers by imploring the editorial team to guide authors to improve the quality of a paper. He always believed that if there was a valid scientific message in these manuscripts; all efforts should be made to help the author present his/her work to the world. His passion for mentorship was not limited to the journal alone. The paper by Waweru describes his work with trainee surgeons of the SSK where he founded the residents' forum and encouraged trainees to network and share knowledge (5).

The AAS editorial team literally grew under his wing having started with a lean team of two members to the current seven. He personally engaged the editors and reviewers many of whom were naïve at the skill. He however guided them through the process of developing a journal issue through several versions and modification of manuscripts. One editor admits to have been encouraged by him even when she thought it was impossible to carry out the task. He instigated the culture of sacrifice and always giving your best even when there was no monetary gain for the benefit of the good. This is evidenced by the editorial team giving voluntary services towards development of the journal.

The AAS has really matured over the years through his commitment. He worked hard to increase its visibility in the international front. We have a team of 14 editorial advisors; 5 of whom hail from outside the African continent. This rich diversity adds quality to the journal. Towards the end of his term, Prof. Saidi presided over several activities that propelled the international standing of the journal. The AAS joined the Africa Journal Partnership Program (AJPP) in 2016. This has laid the foundation for indexing and partnerships with the Research without Borders, a program of Elsevier Foundation which has greatly accelerated the development of the journal.

It goes without saying that the journal has greatly benefited from the immense influence of Professor Hassan Saidi, not only to the editorial team but most importantly to its contributors and readers. His never failing commitment inspires us to take the journal to even higher heights.

\section{References}

1. The Annals of African surgery. Volume 1. www.annalsofafricansurgery.com

2. Green A. Saidi Hassan. The Lancet 2017; 390(10102): 1580

3. Ojuka DK. Contribution of Prof Saidi to Surgical Education in Kenya. Ann Afr Surg 2018; 15(2):7072

4. Kobe IO. Finding The Optimal Paradigm in Surgical Training and Mentorship: Prof. Hassan's Example. Ann Afr Surg 2018; 15(2):46-47

5. Waweru J. Prof Saidi, Founder of the Residents Forum. Ann Afr Surg 2018; 15(2):68-69

6. The Annals of African Surgery. About the Editors.www.annalsofafricansurgery.com 